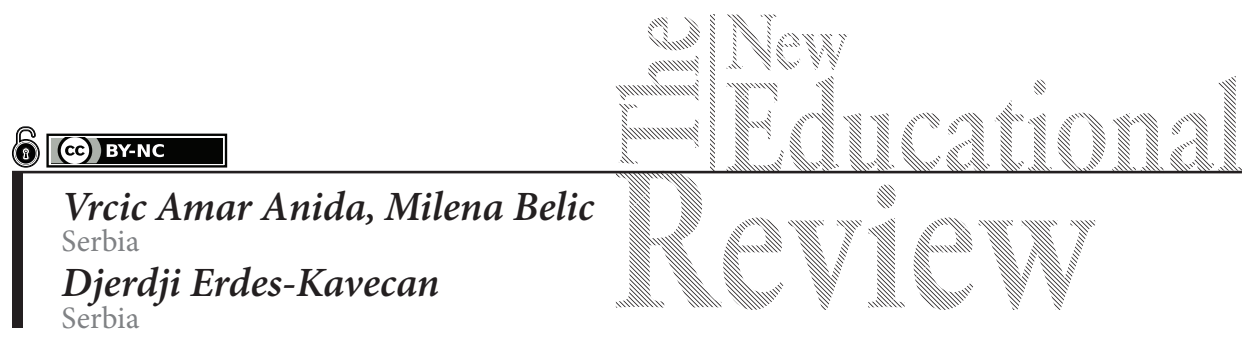

\title{
Concern, Pessimism and Neuroticism of Senior Undergraduates and Students
}

DOI: 10.15804/tner.2021.64.2.22

\begin{abstract}
This paper explores the relations of concern, pessimism and neuroticism in two groups of young people, students in their final year of high school, and senior undergraduates of different faculties. In this research, we further want to check at what level these cognitive elements are expressed in young as well as whether there is a difference between the sexes.

The study included 274 participants, average age of 20 from the South-Western Serbia. The following instruments were used: Scale of optimism / pessimism, Penn state questionnaire of concerns and GEN questionnaire for generalized neuroticism.

The results showed that young people have a higher concern, pessimism, and that $17.9 \%$ of young people in our sample were neurotic. Female gender is more concerned and neurotic when compared to males.
\end{abstract}

Keywords: Neuroticism, concern, pessimism, youth, school, university

\section{Introduction}

In an effort to understand the school context of modern education, which is characterized by transitional changes in the past in Serbia, and which directly reflects on users of the education system, high school students and students, we decided to check some cognitive, behavioral and conative characteristics of adolescents. 
Critical periods during schooling are mainly related to the transition periods from primary to secondary school, from secondary school to faculty, and from the faculty to the world of work. Special emotional investments monitored behaviorally can model a conative structure, and are certainly a source of concern for adolescents in an educational context.

This model of conative function is the synthesis of a reformulating model suggested by Powell and Royce (1982), and Momirović, Horga and Bosnar (1982, 1984).

Finally neuroticism can be defined as the overall efficiency of all systems for the regulation, control and coordination, and is operationally defined as the general factor of higher order in the space of all variables that evaluate different aspects of the (in)efficiency of the systems that determine the conative functioning.

It is possible that the cognitive style is modelled by heightened concern and pessimism as the tendency to interpret the future in the global, specific and negative way of modelling the existing neuroticism. Furthermore, research results in most cases show that increased anxiety during adolescence is shown through inferior social and academic functioning and a high risk of school failure (Laugesen, Dugas, Bukowski, 2003). According to the cross-cultural study testing the relations of concerns, optimism / pessimism in US and Russian adolescents, obtained results showed that the concern is negatively correlated with age, which is explained by gaining experience and building personal strategies. Russian teens show greater concern in global sense in relation to the Americans. The authors explain this data referring to constant social changes in Russia and more expressive collective consciousness (Howard, Sukhodolsky, 1995).

A cognitive state of anxiety, accompanied by a behavioral pessimistic explanatory style, along with neuroticism accompanied by emotional maladaptation and bad mood can be an additional burden for adolescents at a critical moment in their development. The task of the support system through pedagogical psychological practice is to recognize and strengthen cognitive and conative malformations. In this way, we strengthen the school system with a safe atmosphere for all its users and create a sense of belonging to each user at the primary, secondary and tertiary levels of education.

\section{Methodology}

In accordance with the theoretical basis, we decided to check the level of neuroticism, anxiety and pessimism of high school and university students by examining the nature of the relationship between general neuroticism, anxiety and pessimism in this group of respondents. 


\section{Sample}

The study sample consisted of students of final year of secondary schools in Novi Pazar and Sjenica and students of final year of studies of the State University of Novi Pazar from different departments. The study included 274 respondents equal to certain parameters (by gender: female $58 \%-42 \%$ of males; by education: pupils $53.6 \%-46.4 \%$ students), and the average age of respondents was 20 years $(\mathrm{AS}=20.5 ; \mathrm{SD}=2,433)$.

\section{Instruments}

The study will use the following measuring instruments:

The general neuroticism GEN/A; GEN/B - to assess neuroticism we will use the tests GEN/A and GEN/B of the group of authors (Wolf, Momirović, Džamonja, Hošek, 1993). These are two strictly parallel tests to assess general neuroticism - GEN/A and GEN/B. Tests GEN/A and GEN/B can be applied collectively and individually. In GEN test 15 items are selected from every scale saturated by this factor, virtually at random. The items are included in the composition GEN/A. The remaining 15 items are listed on the GEN/B. Both tests contain 75 items. Natural boundaries to determine the classification categories with normally distributed traits are inflection points of distribution function. Therefore, the borders used for this type of diagnostic observations are at \pm of one standard deviation from the average. These borders divide population on $15.87 \%$ of those who are not neurotic (group of non-neurotic), $68.26 \%$ of those whose neuroticism is average (group of average neurotic) and $15.87 \%$ of those who are highly neurotic (a group of neurotic).

Penn state Worry Questionnaire - Penn state Worry Questionnaire will be used to examine the concerns (Penn State Worry Questionnaire-Mayer et all., 1990). The questionnaire consists of 16 statements that measure the propensity to excessive and uncontrollable worry. Eleven claims measure high and uncontrollable worry, while 5 claims are of a reverse direction. The questionnaire is univariate.

Scale of optimism / pessimism - Scale of optimism/pessimism of the author Chang will be used for testing optimism and pessimism (Chang 2002, according to Penezić, 2002). The scale contains 14 items: 6 for assessing optimism and 8 for assessing pessimism. The overall result is formed as a linear combination (sum) of scores on each item, separately for optimism and for pessimism. Results of the research showed that between optimism and pessimism scale there is a high negative correlation, meaning that these two constructs are basically two dimensions, not two sides of the same dimensions. Reliability of the scale for optimism is $\alpha=$ .632 , and for pessimism $\alpha=.728$ 


\section{Results and Discussion}

The average level of neuroticism in our sample is approximately $268(\mathrm{M}=$ $267.81, \mathrm{SD}=41.17)$. Respondents have achieved an average score of $22(\mathrm{M}=21.88$, $\mathrm{SD}=4.94)$ on the pessimism scale, and the average score on the scale of concern is $47(\mathrm{M}=47.07, \mathrm{SD}=7.19)$, indicating an increased concern on the total sample of respondents.

Having in mind that in the description of the instruments we emphasized that the scale of the cybernetic model of general neuroticism is a diagnostic instrument, the analysis of the limit values were determined based on the recommendation of the author (Momirović and associates, 1982), so the limit value for neuroticism is equal to the average value + standard deviation. In our sample, the limit value is 310 , and respondents who achieved the result of over 310 can be seen as neurotic. There are 49 (17.9\%) neurotic respondents in our survey.

Increased levels of concern and pessimism in our sample can be understood as an appeal to help sent by young people to the world that surrounds them. Adolescents, who participated in this study informally, during the research, suggested that they were very concerned and disappointed with the existing social system. Starting from school as part of the macro system in which they function every day, to their natural environment - family, young people are characterized by a pessimistic mood and noticeable concern.

How can we interpret this situation of our youth? The social changes over the past 25 years have made a social climate in which uncertainty and concern follow us day by day. Teenagers, even when they do not want to think about the future, when they are committed to the present and wish to live there in prosperity, worried and pessimistic environments impose their forms of thinking on them. Global dissatisfaction with the poor economic conditions of the local population, including South-Western Serbia like among the least developed parts of Serbia, is present in almost every family. The continuing need to maintain harmonious family continuity of everyday life and distractors that disrupt this continuity can be assumed to cause the increased levels and concerns, and therefore a pessimistic view to the future.

The authors (Brdar, Miljković, Rijevac, 2011) believe the parental explanatory style has a primary influence on a child's development of pessimism. Parental explanatory style, a way of predicting the future, understanding the consequences and analyzing events will affect the adoption of explanatory styles of their children. In case of a fault, pessimistic parents often declare their child as "stupid" or "lazy" which can lead to the situation that a child internalizes these inner, lasting and 
global causes in the future, and considers them to be a reason for her/his failures, thus maintaining pessimistic explanatory style (Seligman, 1995) .

According to the research of Muris (Muris, 2002), the concern as cognitive style is greatly influenced by parents. Increased concern about the lack of material resources and primary care to maintain the unique structure of the family certainly imposes a burden on children and parents. The severity and indulgence as parenting styles cause rebellion, disobedience, resistance, a sense of reduced control, a sense of general insecurity in their own actions, and young people often feel worried and unreliable which is also followed by a strong sense of dependence. It is important to note that this is a fairly conservative environment with a strong influence of the patriarch so both honour and dignity are two very important characteristics of personality that need to be developed. Furthermore, the survey results show a high average neuroticism of adolescents.

According to Malinić (Malinić, 2011) a high level of neuroticism was found in students from Bosnia and Herzegovina in relation to students in Montenegro, which is explained by greater willingness of Montenegrin students to focus on the problem and seek social support. The high level of emotional instability can be interpreted by social changes, especially in the education system as well. If we look at adolescents in the context of education, the pressure they experience with the current changes may result in difficulty in adapting. Very often, the effects of pressure are expressed through anxiety, worry and concern. The need to overcome the requirement of education, which is often changing, forces adolescents to form new coping strategies in order to feel emotionally stable.

The results of age, pessimism, concern and neuroticism are compared to T-test for independent samples. The results are shown in the table.

Table 1. Values for the variables pessimism, concern, and generalized neuroticism at sexes

\begin{tabular}{llll}
\hline \multicolumn{1}{c}{ Males } & \multicolumn{1}{c}{ Females } \\
\hline Variable & $\mathrm{AS} \pm \mathrm{SD}$ & $\mathrm{AS} \pm \mathrm{SD}$ & $\mathrm{P}$ \\
\hline Pessimism & $21.93 \pm 5.09$ & $21.83 \pm 4.83$ & 0.877 \\
\hline Concern & $45.87 \pm 6.82$ & $47.94 \pm 7.34$ & $0.018^{\star *}$ \\
\hline Neuroticism & $260.98 \pm 43.64$ & $272.74 \pm 38.68$ & $0.009^{\star *}$ \\
\hline
\end{tabular}

${ }^{* *} \mathrm{p}<0,01$

The difference of mean values of pessimism between the sexes is not statistically significant ( $p=0.877$ ). The difference of mean values of concern between the sexes 
is statistically significant and female adolescents are more concerned in our sample $(\mathrm{p}=0.018)$. Consistent research reports that female gender is more concerned, so they achieve significantly higher scores than male in tests that measure concerns. Culturally speaking, women are more educated in the "spirit of concern" through constant implication of a sense of security and responsibility that is placed on the woman by the society. In accordance with their upbringing, women will faster develop altruistic motivation that involves love for children, the desire to care for them, to give them love and protection. Hence the increased need of women for protection and care when they are not protected. It is interesting that the research findings show that women have more statements about maladaptive care than of adaptive care (Rueckert, Naybar, 2008). The main reason lies in the fact that women tendency to care is associated with their positive belief about caring. Women, in some cases, possess magical thinking that expressing concern in a way protects them against negative emotions.

In our sample, female adolescents have a higher level of neuroticism compared to male adolescents. This finding is consistent with numerous researche that deal with differences in the level of neuroticism according to sex (Goodwin, Gotlib, 2004; Heaven, Shochet, 1995; Lippa, 2010). Consequently, neuroticism refers to the reduction of attempts to "improve" the current state, to mitigate the bad emotions and maintain good emotions, and in this domain, women are more willing to "fix" the current poor emotional state and to mitigate the effects of negative emotions compared to men (Kokkonen, Pulkkinen, 2001). Recent studies also show that women experience more emotional changes during the day compared to men (Almeida, Kessler, 1998; Mohr et all 2003), and accordingly the greater the number of daily activities during the day, the persons with more pronounced neuroticism will react stronger to events and stimuli (Longua et al., 2009), which may indicate that neuroticism in women may not be in the function of personality trait, but in the function of the number of activities during the day (VanDyke, Gore, 2012).

By T-test for independent samples, we checked whether there are differences between the mean values of neurotic and non-neurotic and variables of pessimism and concern.

The difference between the mean values of pessimism between neurotic and others is statistically significant $(\mathrm{p}<0.05)$.

The difference between the mean values of neurotic and other is statistically significant $(\mathrm{p}<0.05)$. The results are shown in Table 2 .

The assumption that pessimism as an explanatory style will result in elevated neuroticism has its basis in theory and can be seen through the learned helplessness model proposed by Seligman. Namely, if we suppose that every failure 
Table 2. T-test for independent samples for variables of pessimism and concern and categories of neurotic and non-neurotic

\begin{tabular}{llll}
\hline \multicolumn{1}{c}{ Variable } & \multicolumn{1}{c}{ Neuroticism } & Without neuroticism & p \\
\hline The level of pessimism & $17.64 \pm 4.53$ & $22.31 \pm 4.44$ & $<0,05$ \\
\hline The level of concern & $42.24 \pm 5.74$ & $49.70 \pm 6.88$ & $<0,05$ \\
\hline
\end{tabular}

destabilizes us emotionally to a different extent, a school failure, which is not only quantified through school assessment but also through a number of other situations related to the school environment, could contribute to the feeling of helplessness in adolescents. In a situation where we are prevailed with helplessness we tend to make the situation seem catastrophic, and the need for initiation of willing action is almost non-existent.

The causes of an event in the eyes of the pessimist are usually permanent and global which reinforces the emotional discomfort, anxiety, feelings of helplessness, irritability and anxiety.

The study of Marshal found that pessimism correlated with neuroticism, while optimism correlated with extraversion (Marshal at all, 1992).

In numerous studies that have checked the effect of pessimism/optimism on performance, it is proved that optimists tend to use proactive strategy focused on the problem and to plan action (Carver, Schaiver, 1999), compared to pessimists who prefer mainly emotional strategies: avoidance, social support and withdraw from people.

Judging by reports of the research, concerns contribute to both behavioural changes and personality traits. In an experiment which was verifying whether the success in the performance of a target-oriented behaviour was influenced by individual personality traits, it was shown that people with more pronounced neuroticism would choose those actions that increase the level of concern in order to protect themselves against failure (Tamir, 2005).

Similar results were obtained by the authors who reviewed the relationship between intolerance of uncertainty, meta-worry, neuroticism and conditions of concerns among the non-clinical, student population. The results showed that intolerance on uncertainty, meta-worry and neuroticism can significantly predict concern as a character trait or characteristic, whereas intolerance on uncertainty and meta-worry can be considered important mediators in the relationship between neuroticism and concerns as a character trait. In situations when a stressful event is inevitable, intolerance of uncertainty and neuroticism affect metaworry and support the character concerns (de Bruin et all., 2006). 
Using the Pearson correlation coefficient we checked correlation between variables in the study. The results showed that the age is in moderately negative correlation with pessimism, and in positive correlation with general neuroticism. The results are shown in the table.

Table 3. Pearson correlation coefficient to examine the link between the variable of age and pessimism and generalized neuroticism

\begin{tabular}{llcc}
\hline & & r & p \\
\hline Age & Pessimism & -0.168 & 0.05 \\
\hline Age & The general neuroticism & 0.172 & 0.04 \\
\hline
\end{tabular}

The results of our study show that as we get older we are less pessimistic. According to Seligman, a style of explaining good events is invariant during 50 years. As Seligman said, the same person could consider good events as a twist of fate in one period of his/her life, and in another period as consequences of his/her skills. For bad events, the explanatory style is even more durable, more than 50 years we reserve the need to explain bad events. It is assumed that over time we learn to use "defence", characteristic ways in which people struggle with bad events. Mature modes of defense are - humor, altruism, and sublimation. According to the research of the same author, a considerable number of research has shown that the use of these "mature defence" maintains good health and that the individuals who realize it, learn to use these strategies, which directly reduce pessimism (Seligman, 2008).

Research shows that combination of high daily optimism and low daily pessimism is characteristic for youth, which contributes to the greatest emotional benefits for young people, while the relation of high optimism and high pessimism is characteristic for elder people, without combinations characteristic for younger age (Palgi et all., 2011; Chang, 2002). It is likely that over the years we learn that excessive optimism can have two consequences: too much optimism can lead a person to neglect the threat or to overestimate his/her skills in dealing with a difficult situation.

Excessive optimism in the form of fantasies about achieving the goal may discourage people from making concrete plans to achieve the goal (Brdar, Rijevec, Miljković, 2008).

It is also possible that the experience teaches us that defensive pessimism strategy is the best for maintaining mental health. Defensive pessimism conditions the setting of smaller goals and increase of expectations which enhances self-efficacy and belief that they can influence the outcome of events. 


\section{Conclusion}

In accordance with this knowledge, adolescence implies the need of a young man to make more steps at the level of intra-psychic maturity, interpersonal and global social functioning. Violent changes in adolescence will result in the construction of identities through the replacement of the valuation system assumed by parents - in their own system of valuation. During this development period the adolescent is given more autonomy and freedom, which means not only more rights but also more responsibility.

\section{References}

Almeida, D.M., Kessler, R.C. (1998). Everyday stressors and gender differences in daily distress. Journal of Personality and Social Psychology, 75, 670-680.

Brdar, I., Rijavec, M., Miljković, D. (2008). Positive psychology. IEP, Zagreb.

Chang, EC. (2002). Optimism-Pessimism and Stress Appraisal: Testing a Cognitive Interactive Model of Psychological Adjustment in Adults. Cognitive Therapy and Reasrch, Vol. 26 (5), 675-690.

de Bruin, G.O., Rassin, E., Muris, P. (2006). The Prediction of Worry in Non-Clinical Individuals: The Role of Intolerance of Uncertainty, Meta-Worry, and Neuroticism, Vol. 29 (2), 93-100.

Carver, C. S., Scheier, M. F. (1999). Optimism. In C. R. Snyder (Ed.), Coping: The psychology of what works (pp. 182-204). New York: Oxford University Press.

Goodwin, RD., Gotlib, IH. (2004). Gender differences in depression: The role of personality factors. Psychiatry Research, 126, 135-142.

Heaven, PL., Shochet, IM. (1995). Dimensions of neuroticism: Relationships with gender and personality traits. Personality and Individual Differences, 18, 33-37.

Howard.,K., Sukhodolsky.,D.(1995). Optimism, pessimism and worry in Russian and American children and adolescents. Journal of Social Behavior \& Personality, Vol. 10(1), 157-168.

Kokkonen, M., Pulkkinen, L. (2001). Examination of the paths between personality, current mood, its evaluation, and emotion regulation. European Journal of Personality, 15, 83-104.

Laugesen, N., Dugas M., Bukowski W. (2003). Understading adolescente worry. The application of cognitive model. Journal of abnormal Child Psychology. 31(1), 55-64.

Lippa, R.A. (2010). Gender differences in personality and interests: When, where, and why? Social and Personality Psychology Compass, 4, 1098-1110.

Longua, J., Dehar, T., Tennen, H., Armeli, S. (2009). Personality Moderates the Interaction between Positive and Negative Daily Events Predicting Negative Affect and Stress. J Res Pers., 43(4), 547-555.

Malinić, J. (2011). Early experience, personality and school success. Grafid Ltd. Banja Luka. 
Marshall, G.N., Wortman, C.M., Kusulas, J.W., Jeffrey, W., Herwinf L.K. Vickers, J.R., Ross, R. (1992). Distinguishing optimism from pessimism: Relations to fundamental dimensions of mood and personality. Journal of Personality and Social Psychology, Vol 62(6), 1067-1074.

Meyer T.J., Miller M.L., Metzger R.L,, Borkovec T.D. (1990). Development and validation of the Penn State Worry Questionnaire. Behav Res Ther. 28(6), 487-95

Mohr, C. D., Armeli, S., Ohannessian, C., Tennen, H., Carney, A., Affleck, G., Del Boca, F. (2003). Daily interpersonal experiences and distress: Are women more vulnerable?Journal of Social and Clinical Psychology, 22, 393-423

Momirović, K. Horga, S. Bosnar K. (1984). The possibility of synthesis of some theory of personality based on a cybernetic model of conative factors. Man and interest, 4, 3-6.

Momirović, K. Horga, S. Bosnar K. (1982). Contribution to the formation of a cybernetic structure model of cognitive factors. Kinesiology, 14, (5); 83-103

Muris, P. (2002) Parental Rearing Behaviors and Worry Of Normal Adolescents. Psychological Reports: Vol. 91, 428-430.

Palgi,Y., Shrira, A., Ben-Ezra, M., Cohen-Fridel, S., Bodner, E. (2011). The relationships between daily optimism, daily pessimism, and affect differ in young and old age. Peronality and Individual Differences, Vol. 50(8), 1294-1299.

Penezić, Z. (2002) Optimism-Pessimism scale (O-P scale). In: Lacković-Grgin K., Proroković A., Ćubela V., Penezić Z. [ur.] Collection of psychological scales and questionnaires, Zadar: Faculty of Philosophy, 15-17.

Peterson, C., Seligman, M. (1987). Explanatory style and illness. Journal of Personality, 55, 237-265.

Rueckert, L., Naybar, N. (2008). Gender differences in empathy: The role of the right hemisphere. Brain and Cognition, 67, 162-167.

Seligmen, M. (2008). Learend optimism. Zavod za udžbenike i nastavna sredstva, Beograd.

Tamir, M. (2005). Don't worry, be happy? Neuroticism, trait-consistent affect regulation, and performance. Journal of Personality and Social Psychology, Vol 89(3), 449-461.

VanDyke, C.L., Gore, J.S. (2012). Using personality profiles and gender to predict affect. Undergraduate Research. Journal Hum. Sci. 11. 